\title{
Deficient hippocampal insulin signaling and augmented Tau phosphorylation is related to obesity- and age-induced peripheral insulin resistance: a study in Zucker rats
}

\author{
Andrea Špolcová1, Barbora Mikulášková', Katarína Kršková², Lucia Gajdošechová² Štefan Zórad², Rafał Olszanecki , \\ Maciej Suski ${ }^{3}$ Beata Bujak-Giżycka ${ }^{3}$, Blanka Železná and Lenka Maletínská ${ }^{*}$
}

\begin{abstract}
Background: Insulin signaling and Tau protein phosphorylation in the hippocampi of young and old obese Zucker $\mathrm{fa} / \mathrm{fa}$ rats and their lean controls were assessed to determine whether obesity-induced peripheral insulin resistance and aging are risk factors for central insulin resistance and whether central insulin resistance is related to the pathologic phosphorylation of the Tau protein.

Results: Aging and obesity significantly attenuated the phosphorylation of the insulin cascade kinases Akt (protein kinase B, PKB) and GSK-3 $\beta$ (glycogen synthase kinase $3 \beta$ ) in the hippocampi of the fa/fa rats. Furthermore, the hyperphosphorylation of Tau Ser396 alone and both Tau Ser396 and Thr231 was significantly augmented by aging and obesity, respectively, in the hippocampi of these rats.

Conclusions: Both age-induced and obesity-induced peripheral insulin resistance are associated with central insulin resistance that is linked to hyperTau phosphorylation. Peripheral hyperinsulinemia, rather than hyperglycemia, appears to promote central insulin resistance and the Tau pathology in fa/fa rats.
\end{abstract}

Keywords: Zucker fa/fa rats, Insulin resistance, Obesity, GSK-3 $\beta$, Tau protein

\section{Background}

Insulin resistance (IR) is a state during which a higher than normal insulin level is required for glucose homeostasis. IR occurs in the periphery and in the brain, where it has recently been linked to the hyperphosphorylation of the neuronal cytoskeleton protein Tau [1], which is symptomatic for Alzheimer's neurodegeneration. After the glucose homeostasis is disturbed, an increase in the glucose level indicates the onset of type-2 diabetes (T2D).

In several clinical studies, T2D was found to increase the risk of Alzheimer's disease (AD) [2]. In the postmortem brains of both T2D and sporadic AD patients, central resistance to insulin was documented by attenuated insulin signaling, namely via a decreased phosphorylation of

\footnotetext{
* Correspondence: maletin@uochb.cas.cz

${ }^{1}$ Institute of Organic Chemistry and Biochemistry, Prague 166 10, Czech Republic

Full list of author information is available at the end of the article
}

the insulin cascade kinases PDK1 (3-phosphoinositidedependent protein kinase-1), Akt (protein kinase B, PKB), and GSK-3 $\beta$ (glycogen synthase kinase $3 \beta$ ), and this effect was more pronounced in patients with both T2D and AD [3]. GSK-3 $\beta$ acts as both the insulin cascade kinase and the primary kinase phosphorylating Tau $[4,5]$. The phosphorylation of Ser9 in GSK-3 $\beta$ by Akt inhibits the kinase activity of GSK-3 $\beta[6,7]$, and the attenuated phosphorylation of Ser9 logically increases the kinase activity of GSK-3 $\beta$ toward Tau. Central insulin resistance is linked to a hyperphosphorylation of Tau through GSK-3 $\beta$ [8].

Severe hyperinsulinemia and hyperglycemia, as well as the hyperphosphorylation of Ser199/202, Thr231, and Ser396 in Tau, were found to increase progressively with age in the hippocampi of $\mathrm{db} / \mathrm{db}$ mice with impaired leptin receptor signaling, a rodent model of T2D [9]. An augmented phosphorylation of Ser396 in the hippocampal Tau of $\mathrm{db} / \mathrm{db}$ mice was later confirmed by another 
research team [10]. However, in whole-brain samples of $\mathrm{db} / \mathrm{db}$ mice with fully developed T2D, changes in the insulin receptors and GSK-3 $\beta$ phosphorylation were not found [11].

Similar to $\mathrm{db} / \mathrm{db}$ mice, Zucker fatty fa/fa rats have a genetically homozygous leptin receptor mutation that results in leptin dysfunction. Zucker fa/fa rats suffer from obesity induced by hyperphagia, severe hyperlipidemia, and hyperinsulinemia, resulting in IR in the liver, muscle, and adipose tissue [12-14]. The IR in $\mathrm{fa} / \mathrm{fa}$ rats is established prior to adulthood, at the age of 7 weeks [15]. Unlike $\mathrm{db} / \mathrm{db}$ mice, fa/fa rats are normoglycemic or have only slightly elevated glucose levels and do not develop diabetes $[12,13]$.

In this study, insulin signaling and Tau phosphorylation were followed in the hippocampi of 12- (young) and 33-week-old (old) obese Zucker fa/fa rats and their lean controls to verify the hypothesis that peripheral insulin resistance resulting from obesity and/or old age represents a risk factor for central insulin resistance and that such possible central IR is linked to the pathologic phosphorylation of Tau protein. In short, we aimed to determine whether IR with hyperinsulinemia but normoglycemia is associated with a risk of Tau protein pathology in the hippocampus.

\section{Results}

\section{Metabolic parameters}

In old age, both the fa/fa rats and controls developed severe obesity compared with the relevant young controls $\left(\mathrm{F}_{(1,20)}=466.52 ; \mathrm{p}<0.001\right)$. The $\mathrm{fa} / \mathrm{fa}$ rats also showed a significantly higher body weight than did the agematched controls $\left(\mathrm{F}_{(1,20)}=236.30 ; \mathrm{p}<0.001\right)$ (Table 1). As expected, obesity in fa/fa rats resulting from impaired leptin receptor signaling was manifested by hyperleptinemia; thus, a significant age and fa/fa genotype interaction exists $\left(\mathrm{F}_{(1,20)}=12.36 ; \mathrm{p}<0.01\right)$, and a subsequent Bonferroni post-hoc test revealed an increase in the plasma leptin levels in young fa/fa rats compared with young controls $(\mathrm{p}<0.01)$; this increase was more pronounced in old fa/fa rats compared with old controls $(\mathrm{p}<0.001)$ (Table 1). Obesity was accompanied by hyperinsulinemia. There were significant effects of the fa/fa genotype $\left(\mathrm{F}_{(1,20)}=71.66 ; \mathrm{p}<0.001\right)$ and age $\left(\mathrm{F}_{(1,20)}=13.94\right.$; $\mathrm{p}=0.001$ ), as well as an age $\mathrm{x} \mathrm{fa/fa}$ genotype interaction $\left(F_{(1,20)}=7.99 ; p=0.01\right)$ with plasma insulin. Significant hyperinsulinemia in $\mathrm{fa} / \mathrm{fa}$ rats was represented by extreme insulin levels that reached 12 -fold $(\mathrm{p}<0.001)$ at 12 weeks of age and 9-fold at 33 weeks of age $(\mathrm{p}<0.001)$ in lean age-matched controls. The glucose levels in all rats were similar and did not exceed normal values (Table 1). Quantitative insulin sensitivity check index (QUICKI) was significantly decreased in both 12 -week-old obese $(\mathrm{p}<0.05)$ and 33-week-old obese rats $(\mathrm{p}<0.05)$ compared to age-matched lean controls. Both age $(\mathrm{p}=0.002)$ and $\mathrm{fa} / \mathrm{fa}$ genotype $(\mathrm{p}=0.012)$ were accompanied with higher and longer lasting rise in glycaemia during glucose tolerance test as revealed by general linear model for repeated measures. However, there was no interaction between these factors (Figure 1). The impairment in glucose tolerance was assessed also using parameter of 2-h glycemia during IPGTT. This impairment was observed with respect to age $\left(\mathrm{F}_{(1,20)}=19.30 ; \mathrm{p}<0.001\right)$ as well as to fa/fa genotype $\left(\mathrm{F}_{(1,20)}=21.44 ; \mathrm{p}<0.001\right)$. There was no detected effect of an age $\mathrm{x}$ fa/fa genotype interaction. The area under the curve of the glucose level during IPGTT was found to increase due only to the fa/fa genotype $\left(F_{(1,20)}=5.41 ; \mathrm{p}<0.05\right)$.

Dyslipidemia in young and old fa/fa rats was noticed based on the serum lipid parameters. Both total cholesterol $\left(\mathrm{F}_{(1,20)}=120.38 ; \mathrm{p}<0.001\right)$ and cholesterol/HDL ratio $\left(\mathrm{F}_{(1,20)}=23.55 ; \mathrm{p}<0.001\right)$ were significantly increased in $\mathrm{fa} / \mathrm{fa}$ rats compared with lean rats (Table 2). Statistical analysis also revealed that age significantly affected the plasma total cholesterol $\left(\mathrm{F}_{(1,20)}=58.30 ; \mathrm{p}<0.001\right)$ and cholesterol/HDL ratio $\left(\mathrm{F}_{(1,20)}=4.38 ; \mathrm{p}<0.05\right)$. A significant age $\mathrm{x}$ fa/fa genotype interaction significantly affects the plasma total cholesterol $\left(\mathrm{F}_{(1,20)}=42.83 ; \mathrm{p}<0.001\right)$ and cholesterol/HDL ratio $\left(\mathrm{F}_{(1,20)}=6.26 ; \mathrm{p}<0.05\right)$. As revealed in the post-hoc test, both the plasma total cholesterol were significantly increased in young and old fa/fa rats compared with their age-matched lean controls $(\mathrm{p}<0.001)$. An age-dependent increase in this lipid parameter was observed only in $\mathrm{fa} / \mathrm{fa}$ rats $(\mathrm{p}<0.001)$. The cholesterol/HDL ratio was increased in old fa/fa rats compared with their lean age-matched rats $(\mathrm{p}<0.001)$ and

Table 1 Metabolic parameters of fa/fa (obese) rats and their age matched controls

\begin{tabular}{llllll}
\hline Rats & Weight $[\mathbf{g}]$ & Leptin $[\mathbf{n g} / \mathbf{m l}]$ & Insulin $[\mathbf{n g} / \mathbf{m l}]$ & Glucose $[\mathrm{mmol} / \mathbf{l}]$ & QUICKI \\
\hline Young control & $257 \pm 14,17$ & $2,02 \pm 1,23$ & $0,50 \pm 0,24$ & $6,00 \pm 0,42$ & $0,537 \pm 0,071$ \\
Young fa/fa & $386 \pm 13,68^{* * *}$ & $36,72 \pm 5,20^{* *}$ & $6,26 \pm 2,14^{* *}$ & $6,27 \pm 0,63$ & $0,234 \pm 0,008^{*}$ \\
Old control & $457 \pm 21,38^{* * *}$ & $6,33 \pm 1,72$ & $1,43 \pm 0,38$ & $6,38 \pm 0,43$ & $0,274 \pm 0,010$ \\
Old fa/fa & $683 \pm 48,31^{\# \#, \text { ooo }}$ & $88,66 \pm 32,71^{\# \# \#, \text { ooo }}$ & $12,96 \pm 4,50^{\# \# \#, \text { ooo }}$ & $6,80 \pm 0,51$ & $0,216 \pm 0,007^{\circ}$ \\
\hline
\end{tabular}

Data are mean $\pm S D, n=6$ animals per group. Significance is ${ }^{*} \mathrm{P}<0,05,{ }^{* *} \mathrm{P}<0,01$ and ${ }^{* * *} \mathrm{P}<0,001$ ( ${ }^{*}$ vs. young control rats, ${ }^{*}$ vs. young fa/fa rats, ${ }^{\circ} \mathrm{vs}$. old control rats) using two-way ANOVA, Bonferroni post hoc test.

Significance $\mathrm{P}<0.05, \mathrm{P}<0.01$, or $\mathrm{P}<0.001$ is illustrated by one, two, or three symbols, respectively. Particular symbols are for particular groups compared. 


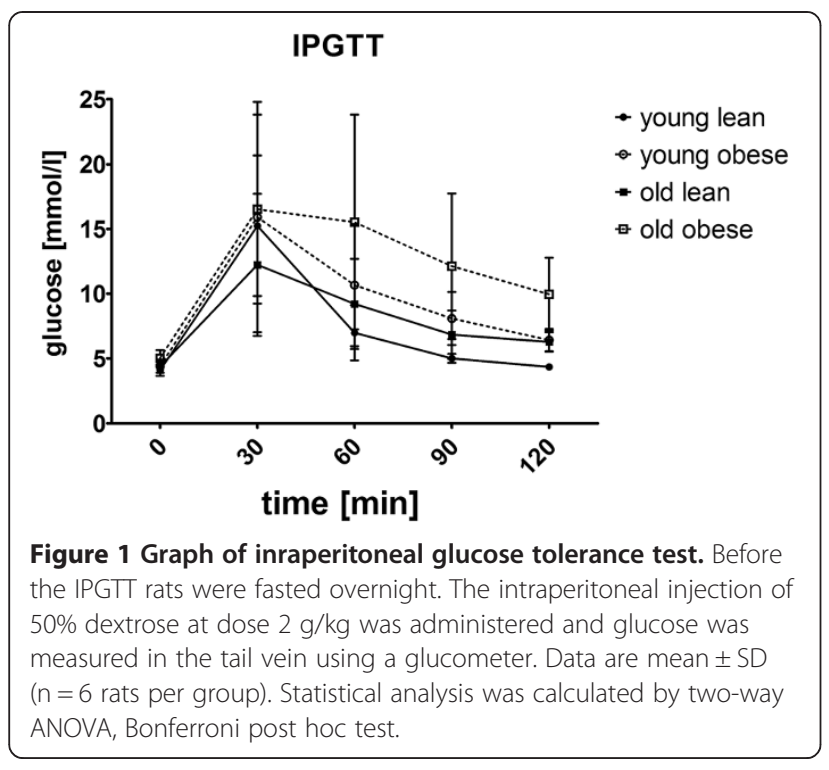

in old fa/fa rats vs. young fa/fa rats $(\mathrm{p}<0.01)$. In the case of plasma triglycerides levels, a significant elevation was noticed only in 33-week-old obese Zucker rats compared to lean rats of the same age.

\section{Insulin signaling cascade in the hippocampus}

Regarding the insulin cascade, a two-way ANOVA revealed a significant main effect of the fa/fa genotype $\left(\mathrm{F}_{(1,20)}=6.82 ; \mathrm{p}<0.05\right)$ on insulin receptor protein expression. In Zucker fatty rats, obesity was associated with lower hippocampal insulin receptor protein levels (Figure 2). However, aging did not affect hippocampal insulin receptor protein expression $\left(\mathrm{F}_{(1,20)}=0.43 ; \mathrm{p}<0.52\right)$. There was no significant interaction between age and genotype $\left(\mathrm{F}_{(1,20)}=0.78 ; \mathrm{p}<0.08\right)$.

Age had a main effect on decreasing the level of PI3 kinase (PI3K) $\left(\mathrm{F}_{(1,20)}=42.03 ; \mathrm{p}<0.001\right)$. The level of PI3K was also attenuated due to the fa/fa phenotype $\left(\mathrm{F}_{(1,20)}=9.84 ; \mathrm{p}<0.001\right)$ (Figure 2 ). The two-way ANOVA revealed a significant interaction between age and

Table 2 Levels of lipids in blood serum of fa/fa (obese) rats and their age matched controls

\begin{tabular}{llll}
\hline Rats & $\begin{array}{l}\text { Cholesterol } \\
{[\mathrm{mmol} / \mathrm{l}]}\end{array}$ & $\begin{array}{l}\text { Triglycerides } \\
{[\mathrm{mmol} / \mathrm{]}}\end{array}$ & Cholesterol/HDL \\
\hline Young control & $2,25 \pm 0,23$ & $0,783 \pm 0,117$ & $1,605 \pm 0,066$ \\
Young fa/fa & $3,40 \pm 0,41^{* *}$ & $2,917 \pm 0,703$ & $1,988 \pm 0,214$ \\
Old control & $2,53 \pm 0,15$ & $0,783 \pm 0,098$ & $1,539 \pm 0,067$ \\
Old fa/fa & $7,08 \pm 1,17^{\# \# \#, \text { ooo }}$ & $4,000 \pm 0,802^{\circ \circ}$ & $2,736 \pm 0,763^{\# \#, ~ o 0 \circ}$ \\
\hline
\end{tabular}

Data are mean $\pm S D, n=6$ animals per group. Significance is ${ }^{*} \mathrm{P}<0,05,{ }^{* *} \mathrm{P}<0,01$ and ${ }^{* * *} \mathrm{P}<0,001$ ( ${ }^{*} \mathrm{vs}$. young control rats, " vs. young fa/fa rats, ${ }^{\circ} \mathrm{vs}$. old control rats) using two-way ANOVA, Bonferroni post hoc test.

Significance $\mathrm{P}<0.05, \mathrm{P}<0.01$, or $\mathrm{P}<0.001$ is illustrated by one, two, or three symbols, respectively. Particular symbols are for particular groups compared. genotype $\left(\mathrm{F}_{(1,20)}=17.77 ; \mathrm{p}<0.001\right)$. Bonferroni's post-hoc test revealed significantly decreased levels of PI3K in young obese rats compared with young lean rats $(\mathrm{p}<0.001)$ and in old lean rats compared with young lean rats $(\mathrm{p}<0.001)$. No significant differences were observed between old obese and old lean rats.

As determined by the two-way ANOVA, there was significant main effect of fa/fa genotype $\left(\mathrm{F}_{(1,20)}=5.00\right.$; $\mathrm{p}<0.05)$ on the phosphorylation of PDK1 Ser241 in the hippocampus (Figure 2). Obesity decreased PDK1 Ser241 phosphorylation in the hippocampi of Zucker fa/fa rats. Neither a significant main effect of age nor an interaction between age and genotype was detected (Figure 2).

The two-way ANOVA revealed a significant main effect of age $\left(\mathrm{F}_{(1,20)}=27.11 ; \mathrm{p}<0.001\right)$ on the phosphorylation of Akt Thr308 (Figure 2). Aging significantly attenuated the hippocampal phosphorylation of Akt Thr308 in both fa/fa and lean rats. Neither a significant effect of genotype $\left(\mathrm{F}_{(1,20)}=0.67 ; \mathrm{p}<0.42\right)$ nor an interaction between age and genotype $\left(\mathrm{F}_{(1,20)}=1.80 ; \mathrm{p}<0.19\right)$ was noted. Regarding the phosphorylation of Akt Ser473, significant main effects of age $\left(\mathrm{F}_{(1,20)}=31.10 ; \mathrm{p}<0.001\right)$ and the $\mathrm{fa} / \mathrm{fa}$ genotype $\left(\mathrm{F}_{(1,20)}=6.51 ; \mathrm{p}<0.05\right)$ were observed. Both aging and obesity attenuated the phosphorylation of Akt Ser473 (Figure 2). There was no significant interaction between age and the fa/fa genotype $\left(\mathrm{F}_{(1,20)}=1.08 ; \mathrm{p}<0.31\right)$.

Similarly, significant main effects of age $\left(\mathrm{F}_{(1,20)}=9.84\right.$; $\mathrm{p}<0.01)$ and the fa/fa genotype $\left(\mathrm{F}_{(1,20)}=12.26 ; \mathrm{p}<0.01\right)$ (Figure 2) on the phosphorylation of GSK-3 $\beta$ Ser9 were observed. Both aging and obesity reduced the phosphorylation of GSK-3 $\beta$ Ser9 (Figure 2). No significant interaction between these factors was detected $\left(\mathrm{F}_{(1,20)}=0.81\right.$; $\mathrm{p}<0.38)$.

\section{Abnormal phosphorylation of tau protein in the hippocampus}

Regarding the phosphorylation of tau at Ser396 in the hippocampus, main effects of age $\left(F_{(1,20)}=21.55\right.$; $\mathrm{p}<0.001)$ and genotype $\left(\mathrm{F}_{(1,20)}=31.16 ; \mathrm{p}<0.001\right)$ were found. Both of these factors increased the phosphorylation of hippocampal tau at Ser396 (Figure 3). There was no significant interaction between age and the fa/fa genotype $\left(\mathrm{F}_{(1,20)}=1.35 ; \mathrm{p}<0.26\right)$. The two-way ANOVA revealed a significant main effect of $\mathrm{fa} / \mathrm{fa}$ genotype $\left(\mathrm{F}_{(1,20)}=8.86\right.$; $\mathrm{p}<0.01$ ) on Tau Thr231 phosphorylation (Figure 3). Obesity significantly increased the phosphorylation of hippocampal Tau Thr231. Neither a significant effect of age $\left(\mathrm{F}_{(1,20)}=0.21 ; \mathrm{p}<0.66\right)$ nor an interaction between age and genotype $\left(\mathrm{F}_{(1,20)}=0.05 ; \mathrm{p}<0.82\right)$ was noted.

\section{Discussion and conclusions}

This study revealed attenuated insulin signaling and increased hyperphosphorylation of Tau (at Ser396 and 


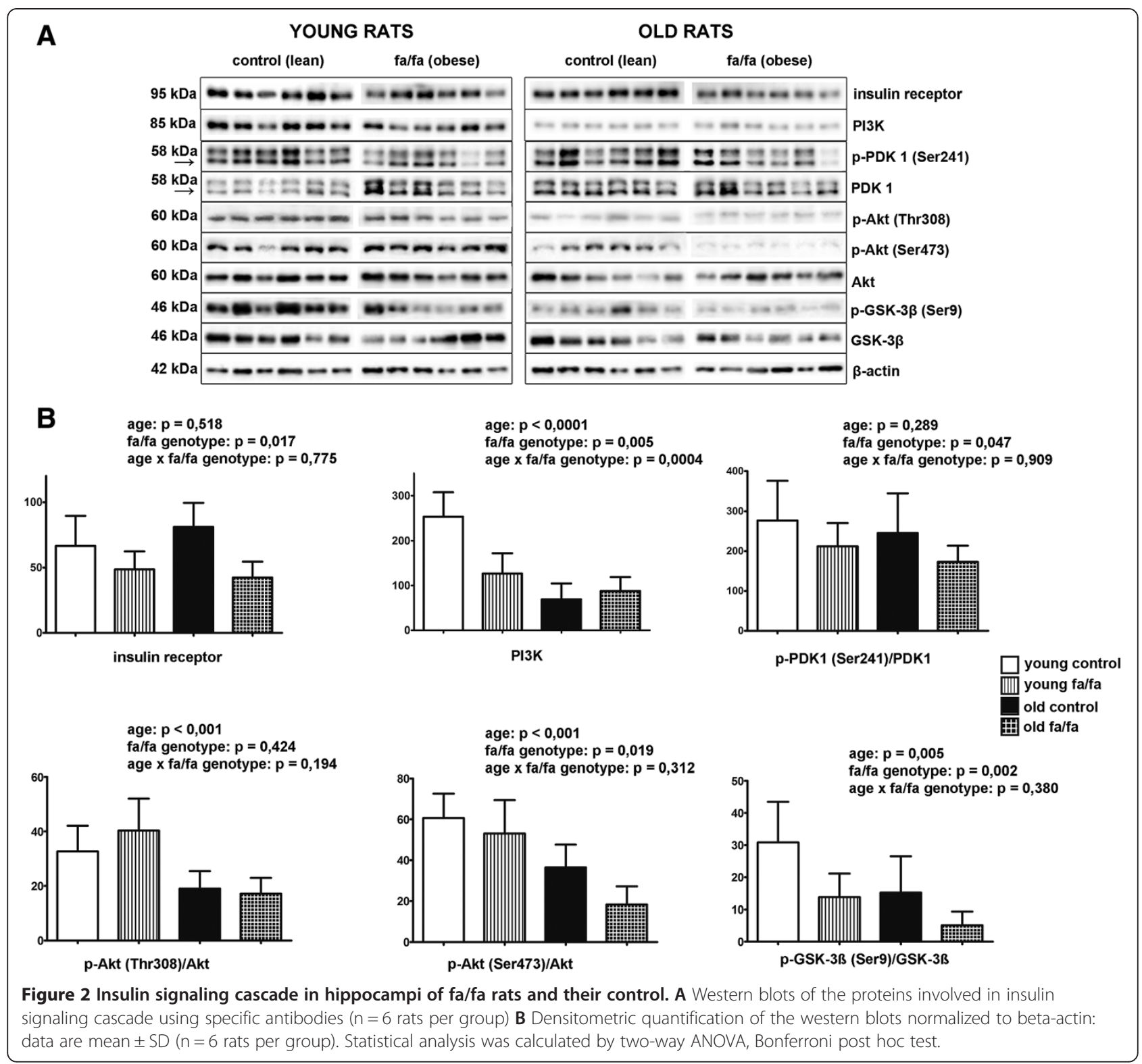

Thr231) in the hippocampi of fa/fa rats exhibiting peripheral insulin resistance or advanced age.

Both the $\mathrm{fa} / \mathrm{fa}$ rats in this study and the $\mathrm{db} / \mathrm{db}$ mice in a previous work [9] exhibited impaired leptin signaling, hyperinsulinemia and blood insulin levels approximately 10 -fold higher than the normal values. These data indicate that peripheral insulin resistance developed at an early age ( 8 and 12 weeks) in the $\mathrm{db} / \mathrm{db}$ mice and the $\mathrm{fa} / \mathrm{fa}$ rats, respectively. IR in the fa/fa rats was indirectly demonstrated using the QUICKI test. Dyslipidemia in the fa/fa rats could be linked to peripheral IR.

The fa/fa rats were normoglycemic even at an advanced age (33 weeks), whereas 8 -week-old $\mathrm{db} / \mathrm{db}$ mice had glucose levels double those of the control $\mathrm{db}+$ mice [9]. Glucose or glucosamine availability is considered to determine the degree of GlcNAcylation of the serines and threonines in the Tau protein that can be phosphorylated [16]. The attenuation of GlcNAcylation in favor of the augmented phosphorylation of the Tau protein has been described as a possible mechanism of Tau pathology [17-19]. On the other hand, healthy mice deprived of food for one to three days (which likely resulted in lower than normal glucose levels) exhibited reversible phosphorylation of hippocampal Tau Ser396 [20]. The $\mathrm{fa} / \mathrm{fa}$ rats in the present study exhibited an obvious increase in the hyperphosphorylation of hippocampal Tau protein in the normoglycemic state. This finding supports the hypothesis that insulin ineffectiveness, rather than extreme glucose levels, is linked to Tau hyperphosphorylation. 


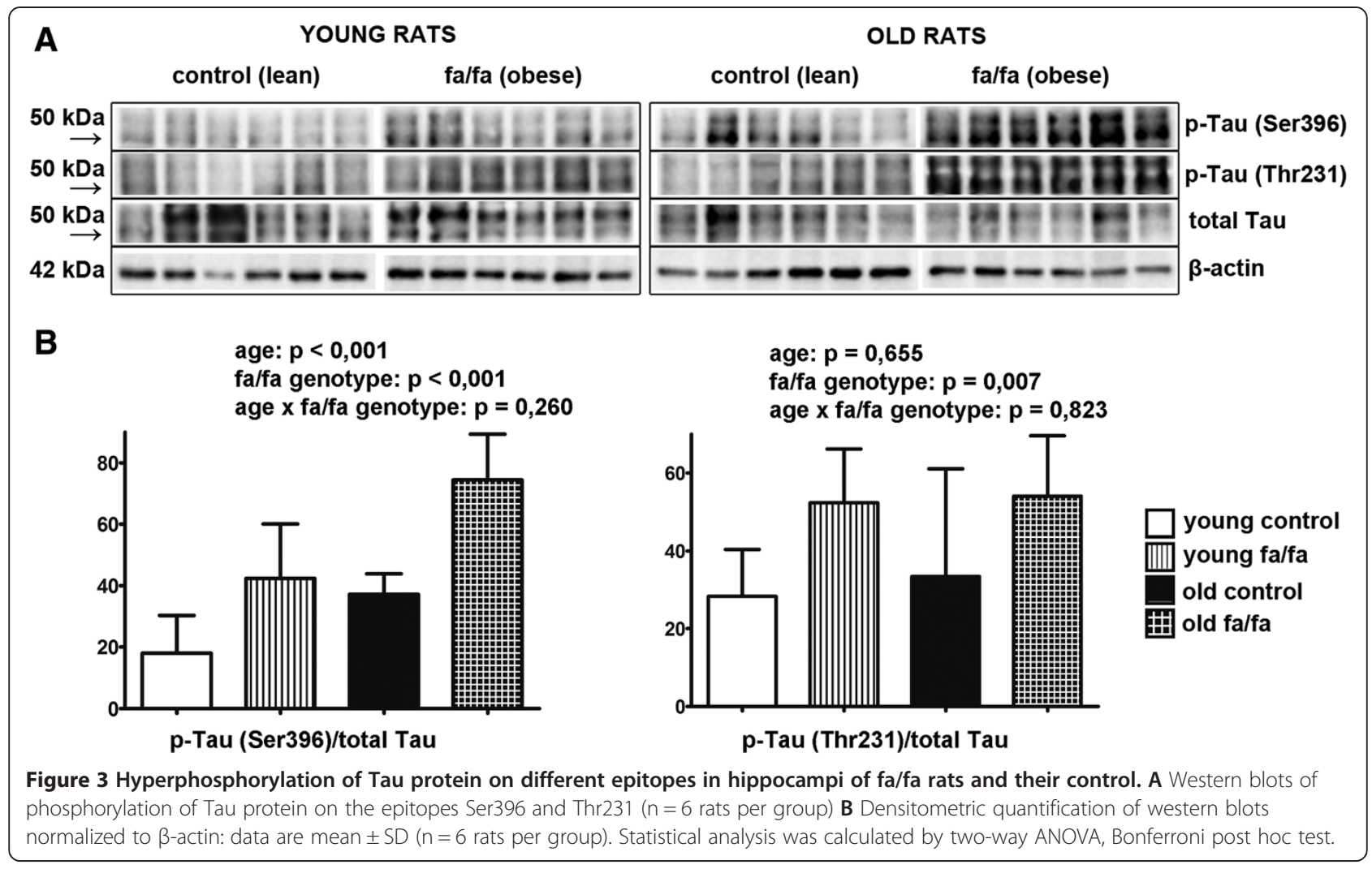

In this study, the obese rats had significantly reduced hippocampal levels of insulin receptor and PI3 kinase protein. Statistically significantly attenuated phosphorylation of both Akt Thr308 and Ser473 was detected in old-age rats, and this effect was more pronounced in $\mathrm{fa} / \mathrm{fa}$ rats. A similar trend was found for the phosphorylation of Ser9 in GSK3/ $\beta$. GSK-3 $\beta$, a kinase common in insulin cascading and Tau phosphorylation, is constitutively active in resting neurons, and its activity is negatively affected by Ser9 phosphorylation [6,7]. GSK-3 $\beta$ is the primary Tau kinase that hyperphosphorylates Tau [21-23], with Ser199, Thr231, Ser396, and Ser413 as the predominant targets [24]. Cavallini et al. [25] identified GSK-3 $\beta$ and also GSK- $3 \alpha$ and MAPK13 as the most active out of 352 kinases overexpressing both Tau kinases and Tau protein [25]. Besides Akt and GSK-3 $\beta$, extracellular signal-regulated kinase (ERK), is involved both in insulin signaling and Tau phosphorylation. However, there were found no differences in ERK1/2 phosphorylation between the groups in this study (not shown).

The Ser396 and Thr231 phosphorylations investigated in this study are essential in Tau protein pathology for the following reasons. Ser396 is directly phosphorylated by GSK-3 $\beta$ without priming (previous phosphorylation of another Ser or Thr on the Tau protein) [26]. Moreover, a positive relationship between the phosphorylation of Tau Ser396 in the cerebrospinal fluid and the severity of the disease was found in AD patients [27]. Additionally, NIRCO (neuron specific knock-out) mice without insulin receptors in brain neurons showed an increase in the phosphorylation of Tau Thr231, which resulted from the attenuated phosphorylation of Akt Ser473 and GSK-3ß Ser9 [5]. Cavallini et al. [25] specified the main phosphorylation sites of Tau as Ser202, Thr231, Ser235, and Ser396/404. In addition to Ser396 and Thr231, we examined Tau phosphorylation at Ser212/ 214 and Ser 202 in all the groups, but the results were inconsistent.

Inefficient leptin signaling in fa/fa rats could contribute to Tau hyperphosphorylation because leptin has been reported to prevent Tau phosphorylation in neuronal cells via the activation of AMP-dependent kinase [28]. This process was later found to be stress dependent [29], making its role in Tau pathology unclear.

This study demonstrated that the phosphorylation of Ser396 and Thr231 in hippocampal Tau was related to the fa/fa obese phenotype; an interaction with the rats' age was found for Ser396 only. Analogously, in the hippocampi of $\mathrm{db} / \mathrm{db}$ mice with non-functioning leptin receptors and severe IR, Tau phosphorylation at Ser 199/202, Thr231, and Ser396 was found to progress with age. Unfortunately, the previous study of 
$\mathrm{db} / \mathrm{db}$ mice [9] did not provide data on hippocampal insulin signaling.

In a human study [3], attenuated insulin signaling was inversely correlated with increased Tau hyperphosphorylation in the frontal cortex of T2D patients, and this correlation was more pronounced in T2D patients with AD co-morbidity. However, data on insulin, glucose, and lipid levels were not accessible because of postmortem sampling. Nevertheless, both impaired insulin signaling and Tau hyperphosphorylation in the brain were obvious in both the human study [3] and this rat study.

Peripheral IR in old-age rats appeared to result in central insulin resistance and Tau hyperprotein phosphorylation in the hippocampus. This effect was more pronounced in obese $\mathrm{fa} / \mathrm{fa}$ rats, which are prone to obesity-induced IR. Based on the normoglycemic state of the IR fa/fa rats, we conclude that a pre-T2D state with IR and normoglycemia is associated with an increased risk of central pathological IR and Tau phosphorylation. The precise mechanism and the role of leptin signaling should be elucidated.

\section{Methods}

\section{Animals}

This investigation was conducted in accordance with ethical standards of the Declaration of Helsinki. This study conformed to national and international guidelines and was approved by the authors' institutional review board. All experimental procedures and animal care were carried out according to the Jagiellonian University Ethical Committee on Animal Experiments (No 75/2011).

Old (33 weeks old) and young (12 weeks old) male obese Zucker $f a / f a$ rats and their age-matched lean controls ( $\mathrm{n}=6$ per each group) were maintained at Jagellonian University in Krakow, Poland. Lean individuals (dominant homozygotes $\mathrm{Fa} / \mathrm{Fa}$ or heterozygotes $\mathrm{Fa} / \mathrm{fa}$ ) served as lean controls for the obese $f a / f a$ rats. The animals had free access to food and water.

The overnight-fasted rats were euthanized by decapitation. The blood glucose was measured at Synlab (Bratislava, Slovakia) using the multi-analyzer COBAS Integra 800 (Roche Diagnostics Ltd., Rotkreuz, Switzerland), and the serum leptin and insulin levels were determined using RIA kits (Millipore, USA) following the manufacturer's instructions. The measurements of the serum lipids were performed in the Laboratory Diagnostics Unit of The University Hospital in Krakow using commercially available kits (Roche Molecular Diagnostics, Pleasanton, CA, USA). The quantitative insulin sensitivity check index (QUICKI) [30] was calculated as QUICKI $=1 /\left[\left(\log \left(I_{0}\right)+\log \left(G_{0}\right)\right]\right.$, where $I_{0}$ is the fasting plasma insulin level (microunits per $\mathrm{mL}$ ), and $\mathrm{G}_{0}$ is the fasting blood glucose level (milligrams per $\mathrm{dL}$ ).

\section{Intraperitoneal glucose tolerance test}

All rats were subjected to an intraperitoneal glucose tolerance test (IPGTT) 2 days prior to euthanasia and after a 16-hour-long overnight fast. The rats were administered an intraperitoneal injection of $50 \%$ dextrose at a dose of $2 \mathrm{~g} / \mathrm{kg}$ body weight. The blood glucose was measured using a glucometer (Accu-Chek Active, Roche Diagnostics, Germany) in the tail vein blood prior to and 30, 60, 90, and 120 min after glucose administration.

\section{Tissue preparation for western blotting}

The dissected hippocampi were homogenized in a glass microhomogenizer using lysis buffer $(62.5 \mathrm{mM}$ Tris$\mathrm{HCl}$ buffer with $\mathrm{pH} 6.8,1 \%$ deoxycholate, $1 \%$ Triton $\mathrm{X}-100,50 \mathrm{mM} \mathrm{NaF}, 1 \mathrm{mM} \mathrm{Na} \mathrm{VO}_{4}$, and Complete Protease Inhibitor (Roche, Switzerland). The lysates were sonicated for $10 \mathrm{~min}$ and boiled for 10 minutes. The samples for electrophoresis at $1 \mu \mathrm{g} / \mu \mathrm{l}$ were diluted with a Laemmli sample buffer containing $50 \mathrm{mM} \mathrm{NaF}$ and $1 \mathrm{mM} \mathrm{Na}_{3} \mathrm{VO}_{4}$.

\section{Antibodies}

The following primary antibodies were used: insulin receptor rabbit mAb, PI3 kinase rabbit Ab, phospho-PDK1 (Ser241) rabbit mAb, PDK1 rabbit mAb, phospho-Akt (Thr308) rabbit mAb, phospho-Akt (Ser473) rabbit mAb, Akt rabbit mAb, phospho-GSK-3 $\beta$ (Ser9) rabbit $\mathrm{mAb}$, and GSK-3 $\beta$ rabbit mAb (all from Cell Signaling Technology, Beverly, MA, USA); phosphoTau (Ser396) rabbit $\mathrm{mAb}$ and phosphoTau (Thr231) rabbit mAb (clone PHF13.6 and PHF-6, respectively, both from Invitrogen, NY, USA); CTer mouse mAb for total Tau protein (gift from Dr. M.-C. Galas, Inserm U837, Lille, France); and beta-actin mouse mAb (from Sigma Aldrich). The following secondary antibodies were used: anti-mouse IgG HRPlinked antibody and anti-rabbit IgG HRP-linked antibody (both from Cell Signaling Technology, Beverly, MA, USA).

\section{Western blotting}

Samples of $2-15 \mu \mathrm{g}$ total protein were subjected to $4 / 10 \%$ SDS-PAGE and transferred onto nitrocellulose (BIO-RAD) or polyvinylidene difluoride (Sigma Aldrich) membranes. The blots were blocked in 5\% non-fat milk or 3\% BSA in a TBS/Tween buffer (20 mM Tris, $136 \mathrm{mM} \mathrm{NaCl}, 0.1 \%$ Tween-20) with $50 \mathrm{mM} \mathrm{NaF}$ and $1 \mathrm{mM} \mathrm{Na}_{3} \mathrm{VO}_{4}$, incubated with the appropriate primary antibody, then incubated with the HRP-linked secondary antibody and developed using the SuperSignal West Femto maximum sensitivity substrate (Pierce, Rockford, IL, USA) following the manufacturer's instructions. The bands were visualized using the ChemiDoc ${ }^{\mathrm{Tw}}$ System (BIO-RAD, Hercules, CA, USA) and were quantified using Image Lab Software (BIO-RAD, Hercules, CA, USA). The band intensities were normalized using actin as an internal loading compound, 
and the ratios of the intensity of the band with the phosphorylated protein and the intensity of the band with the total level of protein were calculated.

\section{Statistical analysis}

The data were analyzed using IBM SPSS 19 Software and are presented as the means $\pm \mathrm{SD}$. The data were tested for normality by Shapiro-Wilk test. Normally distributed data were analysed by two-way analysis of variance with interaction with factors of age and $\mathrm{fa} / \mathrm{fa}$ genotype. Non-normally distributed data were subjected to natural logarithm transformation followed by twoway ANOVA (insulin). Data without normal distribution despite the use of above mentioned transformation were analysed by non-parametric Kruskal-Wallis test (QUICKI, triglycerides). General Linear Model for Repeated Measures was used to evaluate differences in glycaemia during IPGTT. Total area under the curve (AUC) was calculated to describe increment of plasma glucose levels after exogenous glucose load. The overall level of statistical significance was $\mathrm{p}<0.05$.

\section{Competing interests}

The authors declare that there is no competing interest that could be perceived as prejudicing the impartiality of the research reported.

\section{Authors' contributions}

AS performed partly sampling and western blots and partly drafted the manuscript, BB performed western blots, KK performed sampling and partly analyses of the blood samples, LG performed sampling, analyses of the blood samples and partly drafted the manuscript, SZ was partly responsible for conception and design of the study, $\mathrm{RO}$ was partly responsible for the conception and design of the study. BB-G and MS were partly responsible for analyses of the blood samples, BZ and LM partly drafted the manuscript, LM was corresponding author. All authors read and approved the final manuscript.

\section{Acknowledgements}

This project was supported by GACR P303/12/0576 and RVO:61388963 (Czech Rep.), VEGA 2/0089/11 and APW 0028-10 (Slovakia) and 2011/01 M/NZ04/03752 (Poland). The authors are indebted to Dr. M.-C. Galas, Inserm U837, Lille, France for providing the total Tau protein antibody.

\section{Author details}

'Institute of Organic Chemistry and Biochemistry, Prague 166 10, Czech Republic. ${ }^{2}$ Institute of Experimental Endocrinology, Bratislava 833 06, Slovakia. ${ }^{3}$ Jagiellonian University Medical College, Chair of Pharmacology, Krakow 310 08, Poland.

Received: 17 September 2013 Accepted: 18 September 2014 Published: 25 September 2014

\section{References}

1. Deng Y, Li B, Liu Y, Iqbal K, Grundke-lqbal I, Gong CX: Dysregulation of insulin signaling, glucose transporters, O-GIcNAcylation, and phosphorylation of tau and neurofilaments in the brain: Implication for Alzheimer's disease. Am J Pathol 2009, 175(5):2089-2098.

2. Kopf D, Frölich L: Risk of incident Alzheimer's disease in diabetic patients: a systematic review of prospective trials. J Alzheimers Dis 2009, 16(4):677-685.

3. Liu Y, Liu F, Grundke-lqbal I, lqbal K, Gong CX: Deficient brain insulin signalling pathway in Alzheimer's disease and diabetes. J Pathol 2011, 225(1):54-62.
4. Hong $M$, Lee VM: Insulin and insulin-like growth factor-1 regulate tau phosphorylation in cultured human neurons. J Biol Chem 1997, 272(31):19547-19553.

5. Schubert M, Gautam D, Surjo D, Ueki K, Baudler S, Schubert D, Kondo T, Alber J, Galldiks N, Küstermann E, Arndt S, Jacobs AH, Krone W, Kahn CR, Brüning JC: Role for neuronal insulin resistance in neurodegenerative diseases. Proc Natl Acad Sci U S A 2004, 101(9):3100-3105. Epub 2004 Feb 23.

6. Sutherland $C$, Leighton IA, Cohen P: Inactivation of glycogen synthase kinase- 3 beta by phosphorylation: new kinase connections in insulin and growth-factor signalling. Biochem J 1993, 296(Pt 1):15-19.

7. Cross DA, Alessi DR, Cohen P, Andjelkovich M, Hemmings BA: Inhibition of glycogen synthase kinase-3 by insulin mediated by protein kinase $B$. Nature 1995, 378(6559):785-789.

8. Takashima A: GSK-3 is essential in the pathogenesis of Alzheimer's disease. J Alzheimers Dis 2006, 9(3 Suppl):309-317.

9. Kim B, Backus C, Oh S, Hayes JM, Feldman EL: Increased tau phosphorylation and cleavage in mouse models of type 1 and type 2 diabetes. Endocrinology 2009, 150(12):5294-5301.

10. Li J, Deng J, Sheng W, Zuo Z: Metformin attenuates Alzheimer's diseaselike neuropathology in obese, leptin-resistant mice. Pharmacol Biochem Behav 2012, 101(4):564-574.

11. Jolivalt CG, Lee CA, Beiswenger KK, Smith $J$, Orlov M, Torrance MA, Masliah E: Defective insulin signaling pathway and increased glycogen synthase kinase-3 activity in the brain of diabetic mice: parallels with Alzheimer's disease and correction by insulin. I Neurosci Res 2008, 86(15):3265-3274.

12. www.criver.com

13. www.harlan.com.

14. Shiota M, Printz RL: Diabetes in Zucker diabetic fatty rat. Methods Mol Biol 2012, 933:103-123.

15. Di Nardo F, Burattini R, Cogo CE, Faelli E, Ruggeri P: Age-related analysis of insulin resistance, body weight and arterial pressure in the Zucker fatty rat. Exp Physiol 2009, 94(1):162-168.

16. Walgren $\mathrm{J}$, Vincent $\mathrm{TS}$, Schey $\mathrm{KL}$, Buse MG: High glucose and insulin promote O-GICNAc modification of proteins, including alpha-tubulin. Am J Physiol Endocrinol Metab 2003, 284(2):E424-E434.

17. Dias WB, Hart GW: O-GIcNAc modification in diabetes and Alzheimer's disease. Mol Biosyst 2007, 3(11):766-772

18. Deng Y, Li B, Liu F, lqbal K, Grundke-lqbal I, Brandt R, Gong CX: Regulation between O-GlcNAcylation and phosphorylation of neurofilament-M and their dysregulation in Alzheimer disease. FASEB J 2008, 22(1):138-145.

19. Lefebvre T, Dehennaut V, Guinez C, Olivier S, Drougat L, Mir AM, Mortuaire M, Vercoutter-Edouart AS, Michalski JC: Dysregulation of the nutrient/stress sensor O-GlcNAcylation is involved in the etiology of cardiovascular disorders, type2 diabetes and Alzheimer's disease. Biochim Biophys Acta 2010, 1800(2):67-79.

20. Yanagisawa M, Planel E, Ishiguro K, Fujita SC: Starvation induces tau hyperphosphorylation in mouse brain: implications for Alzheimer's disease. FEBS Lett 1999, 461(3):329-333.

21. Ishiguro K, Omori A, Takamatsu M, Sato K, Arioka M, Uchida T, Imahori K: Phosphorylation sites on tau by tau protein kinase I, a bovine derived kinase generating an epitope of paired helical filaments. Neurosci Lett 1992, 148(1-2):202-206.

22. Yamaguchi $H$, Ishiguro $K$, Uchida T, Takashima A, Lemere CA, Imahori K: Preferential labeling of Alzheimer neurofibrillary tangles with antisera for tau protein kinase (TPK) I/glycogen synthase kinase-3 beta and cyclindependent kinase 5, a component of TPK II. Acta Neuropathologica 1996, 92(3):232-241.

23. Hooper C, Killick R, Lovestone S: The GSK3 hypothesis of Alzheimer's disease. J Neurochem 2008, 104(6):1433-1439.

24. Michel G, Mercken M, Murayama M, Noguchi K, Ishiguro K, Imahori K, Takashima A: Characterization of tau phosphorylation in glycogen synthase kinase-3beta and cyclin dependent kinase-5 activator (p23) transfected cells. Biochim Biophys Acta 1998, 1380(2):177-182.

25. Cavallini A, Brewerton S, Bell A, Sargent S, Glover S, Hardy C, Moore R, Calley J, Ramachandran D, Poidinger M, Karran E, Davies P, Hutton M, Szekeres $P$, Bose S: An unbiased approach to identifying tau kinases that phosphorylate tau at sites associated with Alzheimer disease. J Biol Chem 2013, 288(32):23331-23347.

26. Leroy A, Landrieu I, Huvent I, Legrand D, Codeville B, Wieruszeski JM, Lippens G: Spectroscopic studies of GSK3\{beta\} phosphorylation of the 
neuronal tau protein and its interaction with the $\mathrm{N}$-terminal domain of apolipoprotein E. J Biol Chem 2010, 285(43):33435-33444.

27. Hu YY, He SS, Wang X, Duan QH, Grundke-lqbal I, lqbal K, Wang J: Levels of nonphosphorylated and phosphorylated tau in cerebrospinal fluid of Alzheimer's disease patients: an ultrasensitive bienzyme-substrate-recycle enzyme-linked immunosorbent assay. Am J Pathol 2002, 160(4):1269-1278.

28. Greco SJ, Sarkar S, Johnston JM, Zhu X, Su B, Casadesus G, Ashford JW, Smith MA, Tezapsidis N: Leptin reduces Alzheimer's disease-related tau phosphorylation in neuronal cells. Biochem Biophys Res Commun 2008, 376(3):536-541.

29. Salminen A, Kaarniranta K, Haapasalo A, Soininen H, Hiltunen M: AMP-activated protein kinase: a potential player in Alzheimer's disease. J Neurochem 2011, 118(4):460-474.

30. Katz A, Nambi SS, Mather K, Baron AD, Follmann DA, Sullivan G, Quon MJ: Quantitative insulin sensitivity check index: a simple, accurate method for assessing insulin sensitivity in humans. J Clin Endocrinol Metab 2000, 85(7):2402-2410

doi:10.1186/1471-2202-15-111

Cite this article as: Špolcová et al:: Deficient hippocampal insulin signaling and augmented Tau phosphorylation is related to obesity- and age-induced peripheral insulin resistance: a study in Zucker rats. BMC Neuroscience 2014 15:111.

\section{Submit your next manuscript to BioMed Central and take full advantage of:}

- Convenient online submission

- Thorough peer review

- No space constraints or color figure charges

- Immediate publication on acceptance

- Inclusion in PubMed, CAS, Scopus and Google Scholar

- Research which is freely available for redistribution 